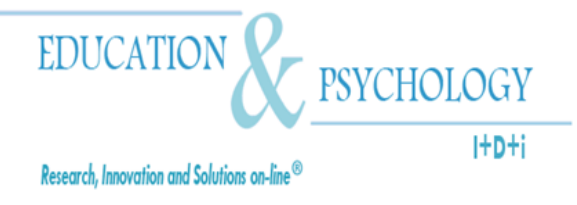

\title{
Future Time Perspective in Sociocultural Contexts: A Discussion Paper
}

\author{
Huy P. Phan
}

School of Education, University of New England, Armidale

\section{Australia}

Correspondence: Huy P. Phan. Senior Lecturer in Learning and Teaching/Educational Psychology. School of Education, Faculty of the Professions. The University of New England. Armidale, NSW 2351. Australia. E-mail: hphan2@une.edu.au

(C) Education \& Psychology $\mathrm{I}+\mathrm{D}+\mathrm{i}$ and Editorial EOS (Spain) 


\begin{abstract}
Future time perspective (FTP) serves as a strong motivational force for individuals to engage in activities that may be instrumental in future outcomes. There has been a voluminous body of research studies, to date, that explored the importance of FTP. This article discusses FTP from sociocultural perspectives. Based on previous empirical evidence, we contend that FTP is related closely to a person's sociocultural identity. We situate our theoretical discussion within the context of the Pacific and argue that a person's FTP is shaped by his/her cultural identity, class and historical origin. Drawing from the evidence cited, we also raise a number of issues and offer directions for future research in this area of inquiry.
\end{abstract}

Keywords: Future time perspective, sociocultural identity, historical origin, Pacific context 


\section{Concepto de futuro en contextos socioculturales: una pro- posición para el debate.}

\section{Resumen}

El concepto de futuro (CF) actúa como una fuente de motivación importante para que los sujetos se involucren en el desarrollo de actividades que serán vitales para los futuros resultados. Hasta la fecha, existe una amplia muestra de estudios que han explorado la importancia del CF. Este artículo discute el Concepto de Futuro desde una perspectiva sociocultural. Basados en evidencias empíricas previas, sostenemos que el CF está estrechamente relacionado con la identidad sociocultural de la persona. Situamos la discusión teórica en el contexto del Pacífico y mantenemos que el Concepto de Futuro personal es moldeado por la identidad cultural y el origen social e histórico. Partiendo de la citada evidencia empírica, también planteamos nuevas temáticas y direcciones para futuras investigaciones en esta área de investigación.

Palabras Clave: Perspectiva de futuro, identidad sociocultural, origen histórico, contexto del Pacífico

Recibido: 09/03/09

Aceptación inicial: 13/03/09

Aceptación final: 28/04/09 


\section{Introduction}

Future time perspective (FTP) theorises the notion that one's sense of purpose for the future serves as a motivational force for individuals to engage in activities that are perceived as being instrumental for future outcomes (McInerney, 2004). For the past few decades, research pertaining to FTP has been instrumental in explaining, in part, students' motivation and academic success. For example, empirical evidence has shown that people's cognitive ability to anticipate both the immediate and long-term outcomes of a task in a distant future is related positively with various motivational, cognitive and performance measures (Andriessen, Phalet, \& Lens, 2006; Horstmanshof \& Zimitat, 2007; Simons, Dewitte, \& Lens, 2004). Anticipating the future, in this analysis, is pivotal as it assists individuals to accomplish personal goals and objectives that may be relevant to their professional development. In his article, "A discussion of Future Time Perspective”, McInerney (2004) poses some fundamental questions that warrant further research and analysis; for example: when do individuals begin to articulate a future?; how far into the future does this articulation extend?; what are the important and essential components of this future?; and do individuals vary in their attention to the future depending on their culture, gender, and socioeconomic status? The latter question is of particular relevance to the Pacific context as it illustrates the importance of FTP, and how this theory may serve as an impetus for individuals to act and behave in this region.

In view of the theoretical and practical implications derived from FTP, this review focuses on the importance of this motivational approach in educational settings. In the first part of this review, we focus on research evidence that pertains to the importance of FTP and how this theoretical facet assists individuals in their academic learning and professional career development. In particular, we focus on research studies (e.g., Cardelle-Elawar, Irwing, \& Sanz, 2007; Phan, 2009; Simons et al., 2004) conducted recently that explored the relations between FTP and other motivational variables and how, in concert, they influence students' academic performances. We attempt to extrapolate and discuss the findings of FTP and their relevance in sociocultural contexts. In particular, we discuss the important implications of FTP in relation to the socioeconomical status of the Pacific, given that this region is going through a period of rapid change. The second part of this review discusses suggestions for future research and theoretical development that could be expanded in FTP research. 


\section{Future Time Perspective: Theoretical overview}

Future time perspective (FTP) theories emphasise people's cognitive ability to anticipate both the immediate and long-term outcomes of task in a distant future (Andriessen et al., 2006; De Volder \& Lens, 1982). Characteristically, FTP relates to individuals' pessimistic and/or optimistic attitudes toward affective and motivational character of the future and its expectations, desires, and fears (Schmidt, Lamm, \& Trommsdorff, 1978; Vázquez \& Rapetti, 2006). In the theoretical discussion of FTP, researchers have often referred to individuals' future anticipation with the notion of 'instrumentality', which is defined as an "instrumental value of a present behaviour" (Husman \& Lens, 1999, p. 116). In this analysis, instrumentality may be referred to as the perception that one's completion of a task or a proximal goal may be instrumental in assisting individuals' future goal attainment. According to Husman and Lens (1999), instrumentality may be differentiated into two different types: (1) exogenous instrumentality - expressing an instrumentality that attributes utility to future goals that closely relate to performance goal orientation, and are extrinsic in nature, and (2) endogenous instrumentality - expressing an instrumentality that attributes utility to future goals that closely relate to mastery goal orientation, and are intrinsic in nature.

The work of Simons and colleagues (Simons et al., 2004; Simons, Vansteenkiste, Lens, \& Lacante, 2004) has further advanced this differentiation, and suggests four different types of instrumentality: low utility - external regulation, low utility - internal regulation, high utility - external regulation, and high utility - internal regulation. In low utility - external regulation, the present task is compulsory and individuals are only driven by extrinsic reasons (e.g., "I want to become a nurse. I'm studying hard for Diet and Nutrition because I have to; it is on the program"). In the second type of instrumentality, low utility - internal regulation, individual are motivated from within (i.e., internal regulation) where learning and performing are goals in themselves (e.g., "I want to become a nurse. I'm studying hard for Diet and Nutrition because of its contribution to my personal development"). The third type of instrumentality, high utility - external regulation, individuals strive for future goals but are driven by extrinsic rewards (e.g., "I'm studying hard for Diet and Nutrition because I want to be a good nurse in order to become chief nurse and have a high status"). Finally, in high utility - internal regulation individuals strive for future goals that internally regulate the present 
action (e.g., "I want to become a good nurse and therefore I'm studying hard for Diet and Nutrition in order to create possibilities (knowledge, abilities, techniques) that will allow me to perform my job as well as possible").

Empirical evidence derived from correlational and experimental research contends that students who perceive the importance of instrumentality of a present task for future goals or tasks are more motivated to persist in their academic learning (Husman \& Lens, 1999; Lens, 2001; Lens, Simons, \& Dewitte, 2002). The theoretical contention, based on these research studies, advocates that individuals who perceive their studies as being instrumental and useful are more likely to be motivated and process learning material in a qualitatively different manner. Furthermore, increased instrumentality in schoolwork is more likely to result positively in conceptual learning, an orientation toward mastery orientation and not ego orientation, and viewing and experiencing one's own schoolwork as enjoyable. There is a collective consensus, based on the findings ascertained, that anticipation of future goals relates positively with academic learning (Miller, DeBacker, \& Greene, 1999; Miller, Greene, Montalvo, Ravindran, \& Nicholls, 1996). The work of Lennings, Burns, and Cooney (1998) involving high school and university students found, for example, that a positive attitude towards the future relates positively with academic achievement. Zimbardo and Boyd's (1999) study of college students, similarly, reported that an emphasis on the future is related to grade point average and hours studying per week. Shell and Husman (2001) in a study involving college students also found that FTP relates positively with grade point average and the time spent doing homework. More recently, Simons et al.'s (2004) study with first-year Nurse students found FTP was related to their task orientation, motivation, persistence, and academic performance. In this analysis, students who found the course they were studying useful for employment were task oriented, showed more motivation in their behaviours, and performed better academically than those who found the course relevant for their training as a student. Likewise, other research studies have shown students who hold strong FTP are more likely to develop an interest in their schoolwork (Andriessen et al., 2006) and to engage in deep processing strategies which, in-turn, may influence their academic achievement (Brown \& Jones, 2004; Horstmanshof \& Zimitat, 2007).

Thus, in general, the evidence cited previously indicates the importance of FTP in affecting students' motivation for learning and professional development. As a theoretical orientation, FTP helps to explain the consequential effects of students' envisage of both immedi- 
ate and long-term goals. In this analysis, apart from motivation, the positive anticipation of short and long-term goals in a distant future guides individuals' behaviours in a right direction. Furthermore, the theoretical orientation of FTP emphasizes the importance of how a person's cognitive ability to anticipate future goals is influenced by his/her sociocultural identity. The sociocultural origin of a person's identity, as many have argued, may be related dialectically to individuals' cognitive time structures that in turn guide progression and development (Seijts, 1998). This theoretical contention reflects the emerging interest in the development of students' learning and motivation from sociocultural perspectives (e.g., Phan, 2008a; Walker, Pressick-Kilborn, Arnold, \& Sainsbury, 2004). This area of research inquiry suggests the notion that motivational development is embedded in individuals' sociocultural contexts. In the subsequent sections of this article, we discuss the context of the Pacific and its relevance to the formation of FTP.

\section{The Pacific Context: FTP and its relevance}

The importance of FTP, as discussed previously, suggests that there are important theoretical and practical implications for both educators and students alike. The Pacific sociocultural context, in particular, serves as a critical point in which FTP may apply and assist individuals in their academic learning and professional development. There is evidence to indicate that FTP originates in a sociocultural context (Lamm, Schmidt, \& Trommsdorff, 1976; Seijts, 1998; Vázquez \& Rapetti, 2006). Accordingly, as an outcome of socialisation, individuals who are more 'socialised' will have learned that their social and cultural class as well as society, in general, expect certain goals and events, some of which are more time specific than others. These goals, subsequently, are selected and integrated into specific cognitive time structures where they become a series of proximal goals toward which progression is then made (Seijts, 1998). In view of this emphasis, we conceptualise FTP in the Pacific context where at the present time this region is undergoing a critical period of change and uncertainty. Socially and economically, this region is influenced by the impact of globalisation and Western cultural values and education. The ongoing problems of financial struggle and poverty have led many to share feelings of discontent, resulting in a lack of disengagement, interest and commitment to work and education. For instance, the sociocultural and historical plight of the Indo-Fijians describes a cycle of insecurity and ongoing discrimination. This perpetuation has resulted in many Indo-Fijian adolescents experiencing despair, discontentment, and disillusion (Phan \& Deo, 2006, 2007). 
The Pacific region at present is conducive to helping many adolescents form their personal experiences, beliefs, expectations, and goals. These ongoing experiences and development may, in turn, help many to develop and establish their own sense of identity. Some would argue (Seijts, 1998; Vázquez \& Rapetti, 2006) that this identity formation is related dialectically to FTP whose importance grows during critical periods that reflect change and uncertainty. In this analysis, we postulate that for many adolescents such as the Indo-Fijians, their identities help determine their own future anticipations and orientations. One could argue, perhaps, that based on the Pacific context, an individual's FTP is based and related closely to a society's contemporary status (Levine \& Bartlett, 1984; Sundberg, Poole, \& Tyler, 1983). Likewise, the same theoretical contention can be made with other adolescents living in other sociocultural contexts.

There has been research over the past few decades that explored FTP in sociocultural contexts. The work of Leshan (1952), for example, suggests that there are important differences between middle and lower social classes in future planning capacity, where the lower class views the future as being uncertain. Research by Vázquez and Rapetti (2006) involving Argentinean adolescents shows that unfavourable social conditions are more than probable to make certain goals unachievable and, subsequently, resulting in a decline in achievement expectation. Despite this line of evidence, there is still a paucity of research concerning the role of FTP among non-Western societies (McInerney, 2004; Phan, 2009).

The sociocultural contexts of the Pacific, as indicated previously, offer a strong emphasis for an expansion of research in the area of FTP. At present, we are aware of only one quantitative research study (Phan, 2009) that has explored FTP in this region. In this study, the author used causal modeling procedures to show the direct and indirect effects of FTP and other motivational variables (e.g., effort) on students' academic performance. Causal modeling, as a statistical method, is more stringent in testing and confirming structural relations between motivational constructs. The results of the study showed that FTP is related positively with deep processing strategies $(\beta=.32)$, effort $(\beta=.21)$, and mastery $(\beta=.31)$ and performance ( $\beta=.30$ for performance-approach, $\beta=.25$ for performance-avoidance) goals. In this analysis, the evidence indicates that FTP is able to explain successfully the learning process and, in part, students' academic performances. Insofar as whether the sociocultural contexts of this region may play a role in the shaping and formation of FTP and its related effects on individuals' motivation and learning is subject to further empirical research and analysis. 
Although students of different ethnic and cultural groups (e.g., Indo-Fijians, Indigenous Fijians, Kiribati) were asked to respond to the Zimbardo and Boyd (1999) Time Perspective Inventory (ZTPI) in the Phan (2009) study, there was no acknowledgment or analysis of the possible effect(s) of social classes or cultures on FTP. There are reasons to suggest, as mentioned previously, that effects of poverty and the ongoing social struggle experienced by many individuals in this region would define and shape their future time perspectives.

Consonant with this postulation, a number of studies (e.g., Phalet \& Claeys, 1993; Phalet \& Hagendoorn, 1996) have explored the academic experiences of Turkish migrants living in Europe. The results indicated, for example, that many Turkish adolescents attach more value to present and future achievement goals than other motivational aspects of development. Furthermore, socioeconomical disadvantage is often followed by sustained achievement striving, along with an increased emphasis on family values and loyalty (Phalet, Andriessen, \& Lens, 2004). In essence, given this conflicting evidence and insight between many Indo-Fijian and Turkish adolescents, further validation and research investigation is needed to explore the possible "two-edge sword" relationship between FTP and socioeconomic status. In conjunction with our theoretical postulation, works previously cited suggest adolescents may react, motivate, and anticipate differently in the sociocultural context of their particular society.

Previous research studies (Mugler \& Landbeck, 1997; Phan \& Deo, 2007; Richardson, Landbeck, \& Mugler, 1995) suggest that Pacific societies at large, play an important role in helping individuals understand the multi purposes of education and learning. In their study, Phan and Deo (2007) argue that the Indo-Fijian students in particular orientate toward a surface learning approach, and reproducing contents for assessment purposes serves as the main impetus for their motivation and learning. This surface learning approach alignment, according to the authors, is perpetuated by the continuous pressure placed by families and communities on Indo-Fijians to compete and excel academically. Education, accordingly, has been inculcated in many Indo-Fijian children at an earlier age as an important key to social and economical mobility (Phan, 2008a; Phan \& Deo, 2007). This indoctrination then prompts many to view the future with a deliberate sense of purpose and conviction, and to ultimately strive for academic excellence (Phan \& Deo, 2008). The envisaged future established at an early age by many children leads to a creation of a fixed mindset, with extrinsic motivation playing a dominant role in learning and professional development. In this analysis, Indo-Fijian children 
differ somewhat from their Pacific Islands counterparts in their earlier onset of future anticipations, as well as the determination to succeed academically in life.

The strong determination by Indo-Fijians to succeed academically is consistent with observations made of other cultural and ethnic groups. It is often the case, as indicated in a number of research studies cross-culturally, that children from aspiring families and community are more likely to be successful in school (Phalet et al., 2004; Vermeulen \& Perlmann, 2000). For many minority children living in the United States, for example, future expectations and the utility of good grades in school often help to overcome social disadvantage and poverty (Day, Borkowski, Punzo, \& Howsepian, 1994; Okagaki \& Frensch, 1998). Furthermore, the work of Ogbu (1992) has introduced the concept of "folk models of success" which explain high academic aspirations as being rooted in the shared history of a particular community (Phalet et al., 2004).

The anticipation or envisagement of a future direction in life does not result, positively, for all individuals in the Pacific. As previously mentioned, the gloomy and desparate socioenomic status of this region has motivated many adolescents to strive for academic success and exellence. However, the two-edge sword of FTP also results in negative effects for many individuals' learning and development. The dire situation has also left many to feel disenfranchised and unsettled. There is, to an extent, a collective feeling of despair and hopelessness that espouses many, leading to a thinking and deliberation that not much of a future exists. Future planning is often perceived as a non-existing phenomenon, which has limited consequences. The anticipation of a future has often been considered as a myth by many college graduates, as there are very few job opportunities upon graduation. With limited career opportunities, many graduates are forced to stay at home and/or to resort to alternative less wellpaid jobs. The limited career prospects available in the Pacific place a strong shadow on individuals' future career planning, decision-making, and organisation. Contributing to the socioeconomical instability of this region, the limitations of career development and life opportunities also influence their cognitive thinking, goal settings, and learning approaches.

Based on the outlined synthesis, one could argue that time perspective is a doubleedge sword in its effects on motivation and learning. The anticipation of a present or a future goal, based on existing research, depends on the sociocultural context and one's historical origin. Cross-cultural research (Leshan, 1952; Phalet \& Claeys, 1993; Phalet \& Hagendoorn, 
1996; Vázquez \& Rapetti, 2006) over the past few decades has provided evidence which attests to the complexity of external influences that shape individuals' future anticipation, thinking, deliberation, expectations and aspirations. The Pacific context, in conjunction with other cultural settings (Day et al., 1994; Phalet et al., 2004), provides an example of the complexity that surrounds time perspective. In this analysis, the ongoing experiences and social conditions of a person's surroundings establish and shape his/her identity. More importantly perhaps, the socioeconomic status of a society may be perceived as a motivational force that could help individuals to strive for academic excellence. However, as we have also documented, the socioeconomical milieu of a society as the Pacific often contributes to discontentment, despair and hopelessness.

\section{Future directions for research in FTP}

The research studies that have been conducted to date reflect the importance of FTP in educational psychology. Likewise, a special edition that was given in the journal, Educational Psychology Review, published in 2004 reflects the importance of FTP (e.g., McInerney, 2004; Simons, Vansteenkiste et al., 2004). The purpose of our theoretical discussion is to further advance this area of inquiry, emphasizing in particular the sociocultural perspective of FTP. Our discussion of FTP involves an examination of this construct and how it fits in with individuals' sociocultural milieus. Our theoretical discussion pertains to previous studies that have explored various educational-motivational constructs from sociocultural perspectives (Phan, 2008b; Walker et al., 2004).

In the preceding sections, we discussed a number of issues concerning FTP and its association with the sociocultural perspectives of the Pacific people. The theoretical contribution made in this review suggests that there are a number of caveats and recommendations that can be advanced further. As indicated earlier, the sociocultural settings of the Pacific have resulted in individuals looking elsewhere for economic vibrancy and development. Unsettling social and political issues arising at the present time contribute to the beliefs held by many that appropriate education would enable economical and social mobility. Consequently, in the mindset of many, academic success is instrumental in perpetuating economic and social development. Furthermore, as we contended previously, individuals' future orientations and attitude are situated contextually and derived from social, personal experiences. Many individuals in this region often experience constant financial limitations and hardship that see 
them develop a fixed attitude to succeed academically, using any alternative learning approaches and/or means (Phan \& Deo, 2007). However, we have also provided an alternative view where the unfavorable situation of the region brings forth negative consequences. With this inconclusive positioning, future research investigations could explore the social and political contextualization of FTP; for example, how does the sociopolitical climate of a particular community or region influence individuals' future positive and/or negative orientations? To what extent does the impact of the sociocultural milieu of the environment contribute to the formation of a person's positive and/or negative FTP?

An alternative argument that has been raised concerns whether, like Asian learners (Watkins, 2000), there is a common ethos shared by a collective group of individuals, such as the Indo-Fijians that may help to explain the formation of FTP. In their theoretical review, Phalet et al. (2004) documented a body of research studies that examined FTP from a cultural perspective. In particular, the authors described the term "family investment" that encompasses a broad set of cultural values, beliefs, and behavioural practices within communities and minorities that motivate and support academic achievements. Furthermore, Phalet et al.'s synthesis of the literature suggests that educational attainment for the Asian people, in general, reflects family honor, prestige and moral virtue (Okagaki, 2001; Schneider \& Lee, 1990). Often the case, as cited in most literature (Bandura, 2002; Markus \& Kitayama, 1991; Phan, 2008a), the Confucianist ethos held by Asian people contributes significantly to their achievements and personal moral well-being. Based on this contention, one could ask whether other cultural and ethnic groups also share a common, collective philosophy or ethos that would shape and influence their beliefs and time orientations over time. Future research studies could investigate, for example, the extent to which shared cultural ideals of a collective group (e.g., Eastern Europeans) influence individuals' decision making, judgments, and present and future goals. Likewise, an individual's sociocultural origin and its dialectically relationship with his/her ethos, philosophy and cultural practices is of relevance to the study of FTP. For instance, how does a person's origin relate to his/her personal philosophical beliefs, values, and aspirations? Is there a reciprocal relationship between these constructs that may then lead to the formation and stability of a person's future orientation?

The study of FTP needs to be approached using various and diverse methodological instruments. Many researchers (e.g., Andriessen et al., 2006; Phan, 2009; Simons et al., 2004) have used quantitative methods and statistical manipulation, such as causal modeling proce- 
dures in their examinations of FTP. Causal modeling procedures are limited as they are based on strong theoretical groundings and empirical evidence, where interpretation of direct and indirect effects reflects the theoretical orientation that defines the directions between variables. Alternative methodological approaches, for example mixed methods (Creswell, 2003; Tashakkori \& Teddlie, 2003), may offer a better insight into the issues that have been identified in this discussion so far. A number of studies (Urdan, 2004; Walker et al., 2004) have recently used qualitative methods to explore motivational constructs in educational settings. Phan's (2008b) research study, for example, used a qualitative method to contextualize students' learning approaches and personal epistemology in sociocultural settings. Future research investigations could adapt a similar approach in the study of FTP and its sociohistorical origin. Likewise, Mugler and Landbeck's (1997) phenomenographical study provided cross-cultural evidence into the sociocultural milieu of the Pacific region, and how socio-historical and cultural influences shaped students' beliefs about learning.

In conclusion, this article offers a number of suggestions for educators and researchers to consider the importance of FTP. There can be no question concerning the positive motivational effects that time perspective has on individuals' personal and professional development. The amalgamation of research evidence across different cultures emphasises the intricacy that FTP features in the community at large. Developing further understanding into FTP in sociocultural texts is pertinent to contemporary societies' well-being. Our examination of the literature offers theoretical insight into the intimate relationship that an individual's historical origin has with his/her future expectations, motivation, and goals. We hope that scholars follow up our key ideas in future research, looking in particular at the social influences of a collective society in the development of FTP. 


\section{References}

Andriessen, I., Phalet, K., \& Lens, W. (2006). Future goal setting, task motivation and learning of minority and non-minority students in Dutch schools. British Journal of Educational Psychology, 76, 827-850.

Bandura, A. (2002). Social cognitive theory in cultural context. Applied Psychology: An International Review, 51(2), 269-290.

Brown, W. T., \& Jones, J. M. (2004). The substance of things hoped for: A study of the future orientation, minority status perceptions, academic engagement, and academic performance of black high school students. Journal of Black Psychology, 30(2), 248-273.

Cardelle-Elawar, M., Irwing, L., Sanz, M. L. (2007). A cross cultural analysis of motivational factors that influence teacher identity. Electronic Journal of Research in Educational Psychology, 13, 5(3), 565-592.

Creswell, J. W. (2003). Research design: Qualitative, quantitative, and mixed methods approaches $\left(2^{\text {nd }}\right.$ ed.). Thousand Oaks, London: Sage Publications.

Day, J. D., Borkowski, J. G., Punzo, D., \& Howsepian, B. (1994). Enhancing possible selves in Mexican-American students. Motivation and Emotion, 18, 79-103.

De Volder, M. L. \& Lens, W. (1982). Academic achievement and future time perspectives as a cognitive-motivational concept. Journal of Personality and Social Psychology, 42, $566-571$.

Horstmanshof, L. \& Zimitat, C. (2007). Future time orientation predicts academic engagement among first-year university students. British Journal of Educational Psychology, 77, 703-718.

Husman, J. \& Lens, W. (1999). The role of the future in student motivation. Educational Psychologist, 34, 113-125. 
Lamm, H., Schmidt, R. W., \& Trommsdorff, G. (1976). Sex and social class as determinants of future orientation in adolescents. Journal of Personality and Social Psychology, 34, 317-326.

Lennings, C. L., Burns, A. M., \& Cooney, G. (1998). The profiles of time perspective and personality: Developmental considerations. Journal of Psychology, 132, 629-641.

Lens, W. (2001). How to combine intrinsic task-motivation with the motivational effects of the instrumentality of present tasks for future goals. In A. Efklides, J. Kuhl, \& R. M. Sorrentino (Eds.), Trends and prospects in motivation (pp. 37-52). Dordrecht, The Netherlands: Kluwer.

Lens, W., Simons, J., \& Dewitte, S. (2002). From duty to desire: The role of students' future time perspective and instrumentality perceptions for study motivation and selfregulation. In F. Pajares \& T. Urdan (Eds.), Academic motivation of adolescents (pp. 221-245). Greenwich, CT: Information Age Publisher.

Leshan, L. L. (1952). Time orientation and social class. The Journal of Abnormal and Social Psychology, 47, 589-592.

Levine, R. V. \& Bartlett, K. (1984). Pace of life, punctuality, and coronary heart disease in six countries. Journal of Cross-Cultural Psychology, 28, 129-137.

Markus, H. R. \& Kitayama, S. (1991). Culture and the Self: Implications for Cognition, Emotion, and Motivation. Psychological Review, 98(2), 224-253.

McInerney, D. M. (2004). A discussion for Future Time Perspective. Educational Psychology Review, 16(2), 141-151.

Miller, R. B., DeBacker, T. K., \& Greene, B. A. (1999). Perceived instrumentality and academics: The links to task valuing. Journal of Instructional Psychology, 26, 250-260. 
Miller, R., Greene, B., Montalvo, G., Ravindran, B., \& Nicholls, J. (1996). Engagement in academic work: The role of learning goals, future consequences, pleasing others, and perceived ability. Contemporary Educational Psychology, 21, 388-422.

Mugler, F. \& Landbeck, R. (1997). Learning in the South Pacific and phenomenography across cultures. Higher Education Research and Development, 16, 227-239.

Ogbu, J. U. (1992). Understanding cultural diversity and learning. Educational Researcher, $21(8), 5-14$.

Okagaki, L. (2001). Triarchic model of minority children's school achievement. Educational Psychologist, 36, 9-20.

Okagaki, L. \& Frensch, P. A. (1998). Parenting and children's school achievement: A multiethnic perspective. American Educational Research Journal, 35, 123-144.

Phalet, K. Andriessen, I., \& Lens, W. (2004). How future goals enhance motivation and learning in multicultural classrooms. Educational Psychology Review, 16(1), 59-89.

Phalet, J. \& Claeys, W. (1993). A comparative study of Turkish and Belgian youth. Journal of Cross-Cultural Psychology, 24, 319-343.

Phalet, J. \& Hagendoorn, L. (1996). Personal adjustment to acculturative transitions: the Turkish experience. International Journal of Psychology, 31, 131-144.

Phan, H. (2008a). Unifying different theories of learning: Theoretical framework and empirical evidence. Educational Psychology, 28(3), 325-340.

Phan, H. P. (2008b). Teaching and learning in the South Pacific: A Vygotskian classroom? In J. Dorovolomo, C. F. Koya, H. P. Phan, J. Veramu, \& U. Nabobo-Baba (Eds.), Pacific Education: Issues and perspectives, pp. 68-91. USP, Lautoka Campus: Max Marketing \& Publishing Ltd. 
Phan, H. P. (2009). Amalgamation of future time orientation, epistemological beliefs, achievement goals and study strategies: Empirical evidence established. British Journal of Educational Psychology, 79, 155-173.

Phan, H. P. \& Deo, B. (2006). Approaches to learning in Educational Psychology and Mathematics: A comparative analysis in the South Pacific region. A refereed article for the Australian Association for Research in Education (AARE) Conference. South Australia, $26^{\text {th }}-30^{\text {th }}$ November 2006, Australia.

Phan, H. P. \& Deo, B. (2007). The revised learning process questionnaire: A validation of a Western model of students' study approaches to the South Pacific context using confirmatory factor analysis. British Journal of Educational Psychology, 77, 719-739.

Phan, H. P. \& Deo, B. (2008). 'Revisiting the South Pacific approaches to learning: A confirmatory factor analysis study. Higher Education Research \& Development, 27(4), $371-383$.

Richardson, J. T. E., Landbeck, R., \& Mugler, F. (1995). Approaches to studying in higher education: A comparative study in the South Pacific. Educational Psychology, 15, 417432.

Schneider, D. \& Lee, Y. (1990). A model of academic success: The school and home environment of East-Asian students. Anthropology and Education Quarterly, 21, 358-377.

Schmidt, R., Lamm, H., \& Trommsdorff, G. (1978). Social class and sex as determinants of future orientation in adults. European Journal of Social Psychology, 8, 71-90.

Seijts, G. H. (1998). The importance of future time perspective in theories of work motivation. The Journal of Psychology, 13(2), 154-168.

Shell, D. F. \& Husman, J. (2001). The multivariate dimensionality of personal control and future time perspective beliefs in achievement and self-regulation. Contemporary Educational Psychology, 26, 481-506. 
Simons, J., Dewitte, S., \& Lens, W. (2004). The role of different types of instrumentality in motivation, study strategies, and performance: Know why you learn, so you'll know what you learn! British Journal of Educational Psychology, 74, 343-360.

Simons, J., Vansteenkiste, M., Lens, W., \& Lacante, M. (2004). Placing motivation and future time perspective theory in a temporal perspective. Educational Psychology Review, $16(2), 121-139$.

Sundberg, N. O., Poole, M. E., \& Tyler, L. E. (1983). Adolescents' expectations of future events: A cross-cultural study of Australians, Americans, and Indians. International Journal of Psychology, 18, 415-417.

Tashakkori, A. \& Teddlie, C. (2003). Handbook of mixed methods in social and behavioral research. Thousand Oaks, London: Sage Publications.

Urdan, T. (2004). Using multiple methods to assess students' perceptions of classroom goal structures. European Psychologist, 9(4), 222-231.

Vázquez, S. M. \& Rapetti, M. V. (2006). Future time perspective and motivational categories in Argentinean adolescents. Adolescence, 41, 511-532.

Vermeulen, H. \& Perlmann, J. (2000). Immigrants, schooling and social mobility: Does culture make a difference? London: MacMillan.

Walker, R. A., Pressick-Kilborn, K., Arnold, L. S., \& Sainsbury, E. J. (2004). Investigating motivation in context: Developing sociocultural perspectives. European Psychologist, 9, 245-256.

Watkins, D. (2000). Learning and teaching: A cross-cultural perspective. School Leadership and Management, 20(2), 161-173.

Zimbardo, P. G. \& Boyd, J. N. (1999). Putting time in perspective: A valid, reliable individual-differences metric. Journal of Personality and Social Psychology, 77(6), 1271-1288. 